\title{
АНАЛИЗ ТОРГОВО-ЭКОНОМИЧЕСКИХ ОТНОШЕНИЙ МЕЖДУ РОССИЕЙ И ИСЛАМСКОЙ РЕСПУБЛИКОЙ ИРАН
}

\section{(C) 2020 Никифорова Наталья Александровна}

кандидат экономических наук, доцент, профессор Департамента бизнес-аналитики Финансовый университет при правительстве Российской Федерации», Россия, Москва E-mail: nanikiforova@fa.ru

Целью статьи является анализ текущего и перспективного торгово-экономического сотрудничества между Россией и Исламской Республикой Иран (ИРИ). В статье приведена характеристика преимуществ от вступления в силу Временного соглашения, ведущего к образованию зоны свободной торговли между Евразийским экономическим союзом и его государствами-членами, с одной стороны, и Исламской Республикой Иран, с другой стороны. Дан развернутый анализ торговоэкономического сотрудничества между двумя странами.

Ключевые слова: торгово-экономические отношения между Россией и Ираном, анализ товарооборота, анализ таможенных и тарифных льгот.

Отношения между Россией и Ираном имеют длительную историю, однако, на современном этапе развитие этих отношений приобрело особую актуальность. Вступление в силу Временного соглашения, ведущего к образованию зоны свободной торговли между ЕАЭС и Ираном, дало дополнительный стимул к развитию торговоэкономических отношений России и Ирана.

Россия и Иран работают над расширением сотрудничества во всех отраслях, включая финансово-банковскую сферу, промышленность, энергетику, транспорт, сельское хозяйство. Торговый оборот между нашими странами растет и в 2019 году он вырос более, чем на 7\%. Наивысшими темпами растет товарооборот в области сельского хозяйства - в 1,5 раза к уровню 2018 года.

23 апреля 2018 года опубликовано Распоряжение № 739-р «О подписании Временного соглашения, ведущего к образованию зоны свободной торговли между Евразийским экономическим союзом и его государствами-членами, с одной стороны, и Исламской Республикой Иран, с другой стороны». Это Соглашение носит временный характер (сроком на три года) и предусматривает образование зоны свободной торговли по ограниченной номенклатуре товаров между ЕАЭС и Ираном. Данное соглашение начало действовать с 27.10.2019 года.

Это событие существенно влияет на инте- грационные процессы развития бизнеса России и Ирана на основе партнерства и ведут к изменениям инвестиционной политики для наших стран.

Главное отличие Временного соглашения от обычных соглашений о формировании ЗСТ состоит в том, что снижение или устранение таможенных пошлин будет осуществлять не практически по всем товарам, а лишь по некоторым.

Временное соглашение с Ираном предусматривает постепенный переход к полноценной зоне свободной торговли и планируется в два этапа:

1 этап - Временное соглашение длительностью в 3 года.

2 этап - Подписание полноформатного соглашения о ЗСТ между Евразийским экономическим сообществом и Ираном, в случае, если преференциальные условия торговли окажутся эффективными для обеих сторон [1].

Для решения различных правовых вопросов реализации Временного соглашения предусматривается формирование Совместного комитета (СК). Необходимо обеспечение бизнес диалога на уровне СK для всестороннего анализа эффективности мер, предусмотренных Временным соглашением.

Временное соглашение предусматривает ряд обязательств, выполнение которых будет способствовать повышению прозрачности и

\footnotetext{
* Статья подготовлена по результатам исследования в рамках НИР «Расширение взаимовыгодного торговоэкономического сотрудничества между Россией и Ираном», выполненного за счет бюджетных средств по государственному заданию Финуниверситета.
} 
транспарентности торговли:

- предварительная публикация проектов планируемых мероприятий, с возможностью комментариев по ним от другой стороны;

- предоставление в течение 45 дней с момента получения запроса полной информации о планируемых мероприятиях;

- публикация в течение 6 месяцев с момента вступления в силу Временного соглашения пошаговой инструкции для экспортеров сторон.

Ожидаемым эффектом от реализации правовых положений временного соглашения является повышение прозрачности и предсказуемости торговли. А формирование площадок для взаимодействия представителей бизнес сообщества ЕАЭС и Ирана будет способствовать более тесному сотрудничеству, что положительно скажется на развитии торговых отношений.

В соответствии с Временным соглашением устанавливаются следующие принципы торговли между ЕАЭС и Ираном:

- предоставление режима наибольшего благоприятствования в сфере торговли;

- ограничение величины экспортных и импортных пошлин;

- обеспечение свободы транзита товаров;

- недопущение злоупотреблений со стороны государственных торговых компаний и монополий;

- отказ от необоснованных ограничений в отношении товаров, относящихся к сфере преференциальной торговли [2].

Так как Временное соглашение имеет неко-

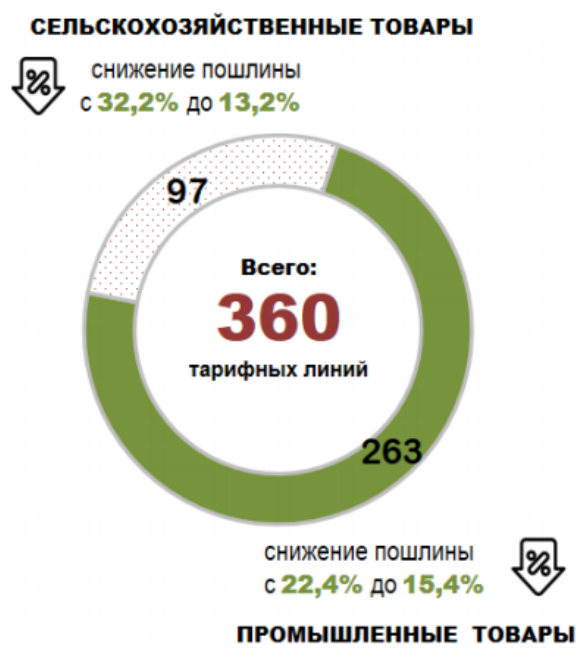

торые ограничения, то снижение или отмена таможенных пошлин охватят более 50\% товарооборота между Ираном и ЕАЭС.

Основную часть товаров, по которым предусмотрены преференции со стороны Ирана, составляют: мясо, масло, жир, шоколад, некоторые виды кондитерских изделий, металлы, косметика, определенные виды механического оборудования и электроники.

На рисунке 1 представлены тарифные уступки со стороны Ирана для экспортеров ЕАЭС.

Так, по промышленной продукции в среднем величина ввозных пошлин Ирана уменьшится с $22,4 \%$ до $15,4 \%$; а по продукции сельского хозяйства - с 32,2\% до $13,2 \%$.

В свою очередь, тарифные обязательства ЕАЭС распространяются на следующие группы товаров из Ирана: овощи, фрукты, сухофрукты, строительные материалы, посуда, ковры, определенные изделия из цветных металлов.

Тарифные уступки ЕАЭС для экспортеров Ирана представлены на рисунке 2.

Так, по промышленной продукции в среднем величина ввозных пошлин ЕАЭС снизится с $8 \%$ до $4,7 \%$; а по продукции сельского хозяйства - с 9,6\% до $4,6 \%$.

Стоит отметить, что в охват Временного соглашения были включены группы товаров, представляющих экспортный интерес сторон. Поэтому снижение или отмена таможенных платежей по данным товаром будет стимулировать увеличение товарооборота между ЕАЭС и Ираном.

В будущем целесообразно внедрить элек-

\section{2,1 млрд \$}

общий ЭКСПОРТ из ЕАЭС в Иран в 2016 - 2018 rr.

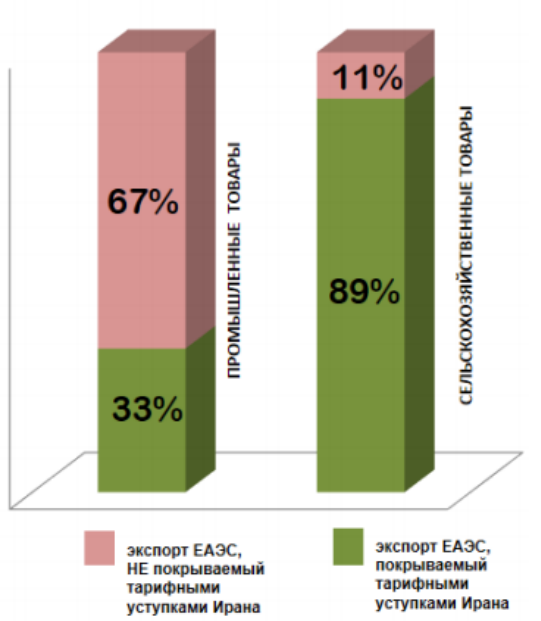

Рисунок 1. Тарифные уступки Ирана [2] 

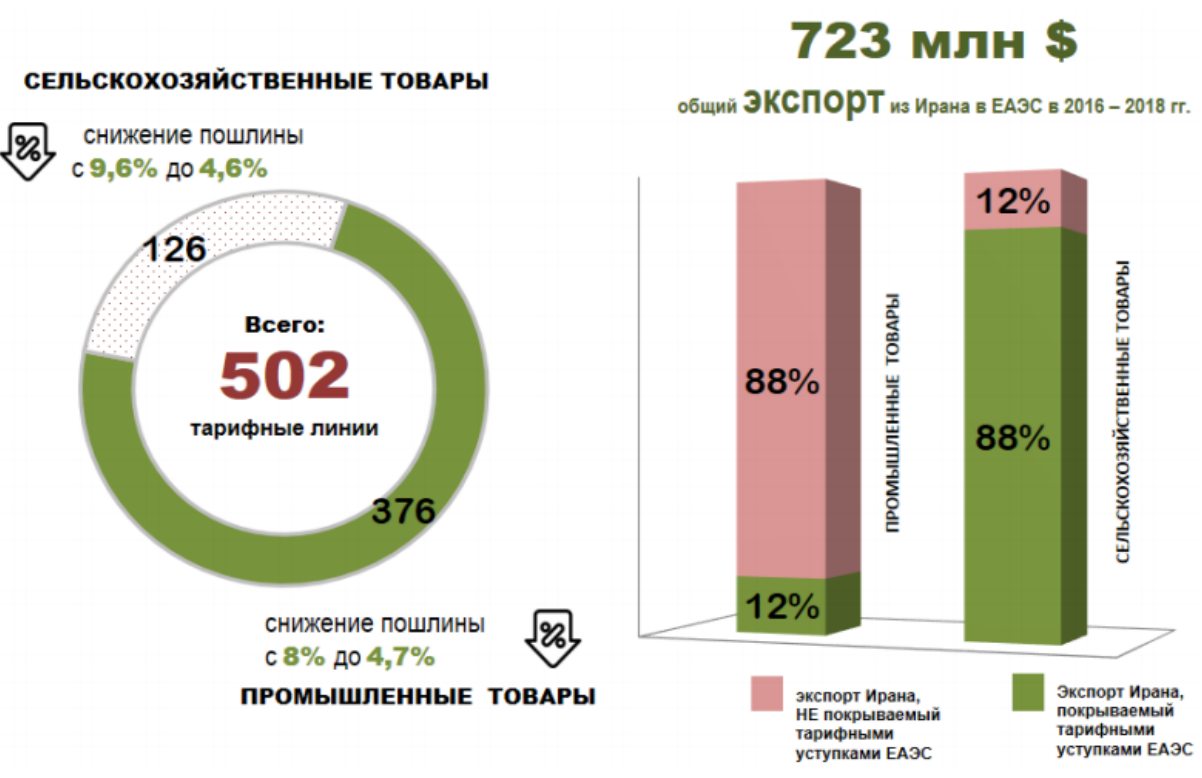

Рисунок 2. Тарифные уступки ЕАЭС [2]

тронную систему сертификации происхождения товара, что упростит процедуру подтверждения страны-экспортера для получения таможенных льгот.

Положительное влияние на качество торговых отношений между странами ЕАЭС и Ираном может оказать заключение договоров о более оперативном выпуске товаров, об активном внедрении средств автоматизации, минимизации бумажного документооборота при таможенном оформлении. Это позволит сократить финансовые издержки, а также ускорить процедуры экспорта и импорта.

Административное сотрудничество таможенных органов стран ЕАЭС и Ирана будет способствовать росту эффективности таможенного контроля, повышению прозрачности и достоверности таможенных деклараций, обеспечению защиты интересов экспортеров и импортеров.

Временное соглашение предусматривает также соблюдение сторонами требований Всемирной торговой организации (ВТО) по обеспечению торговой защиты.

При проведении защитных расследований по поводу импорта из ЕАЭС, Иран будет применять меры торговой защиты в отношении конкретной страны, а не Союза в целом.

Также предусмотрена возможность введения двусторонних защитных мер в случае риска нанесения ущерба в связи с ростом поставок, в результате устранения или снижения таможенных пошлин. Так, возможно временное повышение таможенных пошлин до непреференциального уровня в случае негативного эффекта от роста импорта.

Временное соглашение по образованию зоны свободной торговли между ЕАЭС и Ираном будет способствовать развитию транспортнологистической инфраструктуры сторон. Это должно, прежде всего, оказать положительное влияние на развитие международного транспортного коридора «Север-Юг». Морской путь предполагает развитие транспортного коридора через Каспийское море, соединяющее Иран и Россию.

Объемы торговли между Исламской Республикой Иран (ИРИ) и Россией имеют очень маленькую долю, составляющую около 1\% в общей структуре торговли Ирана. Данный показатель упал с 3 млрд. долларов в 2011-х до одного млрд. долларов в 2014-м. Иран продает в Россию фрукты, фисташки, переработанные плодоовощные продукты, табак, минеральные и некоторые строительные материалы. Однако, укреплению российско-иранских отношений способствуют интенсивно развивающиеся экономические и культурные взаимосвязи. Речь идет о сотрудничестве в самых различных областях - от атомной и тепловой энергетики, нефтегазовой отрасли, промышленного сектора транспорта до сельского, лесного, рыбного хозяйства, связи, экологии и науки. В вузах России открываются кафедры персидского языка (фарси), а в иранских учебных заведениях - русского. В Москве, Тегеране, Исфахане, Санкт-Петербурге, а также 
в других, в том и числе и отдаленных от центра, городах Ирана и России проводятся кинофестивали и устраиваются художественные выставки [3].

В таблице 1 представлены данные по товарообороту России с Ираном за 2017-2019 гг.

Так, в 2018 году общий объем товарооборота вырос на 2,22\%, но в 2019 году снизился на $45,59 \%$ и составил 949,36 млн. долл.

На рисунке 3 представлена динамика экспорта и импорта России с Ираном за 2017-2019 гг.

По данным рисунка 3 видно, что в структуре товарных отношений России и Ирана преобладает экспорт из России. В 2018 году он составил 1207,24 млн. долл., но в 2019 году снизился на $42,8 \%$ и составил 690,58 млн. долл. Величина импорта в Россию из Ирана в 2019 году составила 258,78 млн. долл.

В рейтинге стран - торговых партнеров России Иран находится на 48 позиции с долей оборота $0,3 \%$.

В региональном разрезе основная доля товарооборота России и Ирана приходится на Москву (30,5\% за 2017-2019 гг.), Астраханскую область (12,9\%), Ростовскую область (6,3\%), Челябинскую область (5,5\%), Санкт-Петербург (5\%).

На рисунке 4 представлена товарная структура экспорта из России в Иран за 2017-2019 гг. и на рис. 5 - структура импорта.

Так, основную часть экспорта из Российской Федерации в Иран составляют:
- продукты растительного происхождения (37\%);

- жиры и масла (19,6\%);

- металлы и изделия из них $(11,7 \%)$;

- древесина и изделия из дерева (8,6\%);

- машины и оборудование (7,6\%).Большую часть импорта из Ирана в Россию составляют следующие группы товаров:

- продукты растительного происхождения $(68,5 \%)$;

- металлы и изделия из них (9,4\%);

- продукты химической промышленности $(3,9 \%)$;

- пищевые продукты (3,8\%).

Таким образом, в 2018 году общий объем товарооборота между Россией и Ираном вырос на $2,22 \%$, но в 2019 году снизился на $45,59 \%$ и составил 949,36 млн. долл.

Чтобы оценить всю составляющую инвестиционной привлекательности Исламской республики Иран для российских компаний, проведем еe SWOT-анализ (рис. 6).

SWOT-анализ, позволяет сгруппировать основные возможности и угрозы [5] для потенциальных российских партнеров, планирующих вести свой бизнес в Иране.

Восстановление экономики Ирана после снятия санкций привело к увеличению экспортного потенциала нефти страны, следовательно, это поднимет экономику и Иран позволит себе создать резервы для поддержания других отрас-

Таблица 1. Товарооборот России и Ирана за 2017-2019 гг., млн. долл. [4]

\begin{tabular}{|l|c|c|c|c|c|c|c|}
\hline \multirow{2}{*}{ Показатель } & \multicolumn{3}{|c|}{ Год } & \multicolumn{2}{c|}{ Изменение, +/- } & \multicolumn{2}{c|}{ Изменение, \% } \\
\cline { 2 - 9 } & 2017 & 2018 & 2019 & 2018 к 2017 & 2019 к 2018 & 2018 к 2017 & 2019 к 2018 \\
\hline Экспорт & 1314,9 & 1207,24 & 690,58 & $-107,66$ & $-516,66$ & $-8,19$ & $-42,80$ \\
\hline Импорт & 392,21 & 537,71 & 258,78 & 145,5 & $-278,93$ & 37,10 & $-51,87$ \\
\hline Товарооборот & 1707,11 & 1744,95 & 949,36 & 37,84 & $-795,59$ & 2,22 & $-45,59$ \\
\hline
\end{tabular}

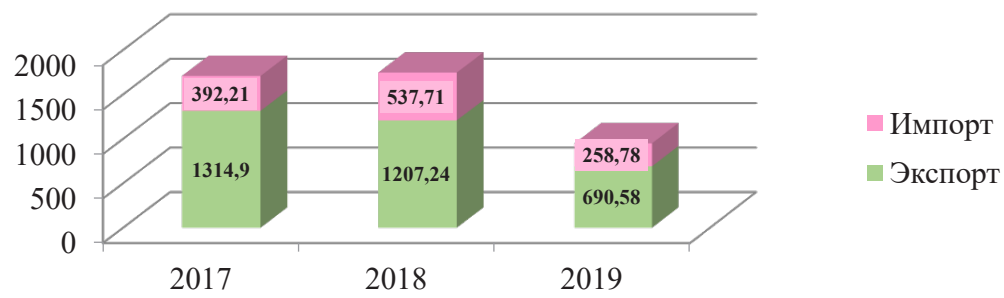

Рисунок 3. Динамика экспорта и импорта России и Ирана за 2017-2019 гг., млн. долл. Источник: составлено автором. 


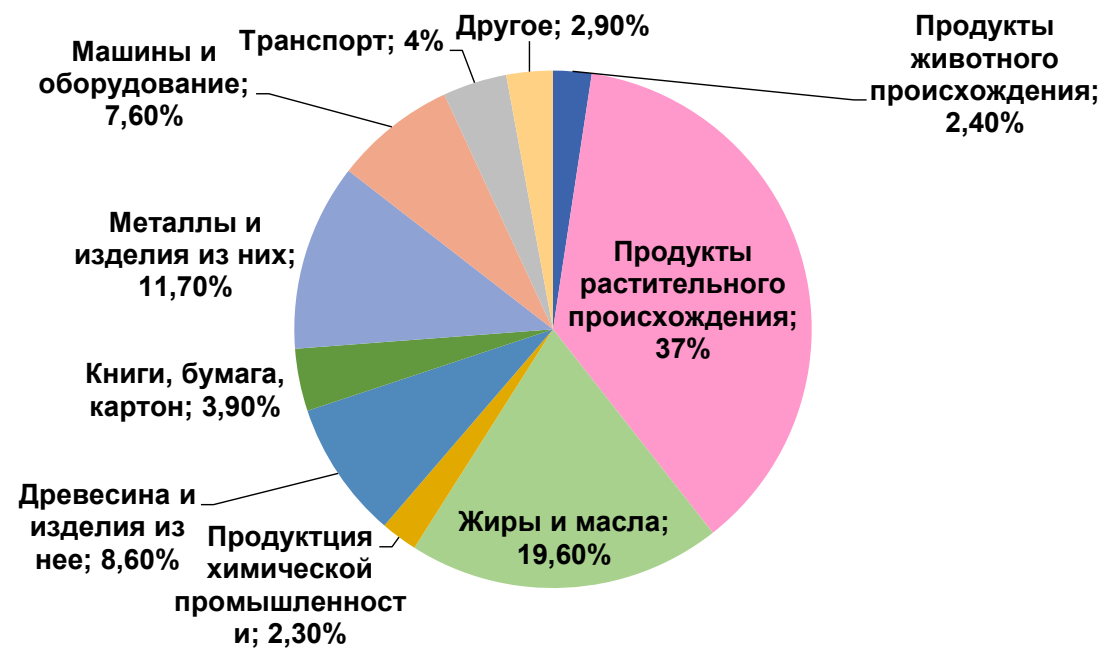

Рисунок 4. Товарная структура экспорта из России в Иран, \% Источник: составлено автором

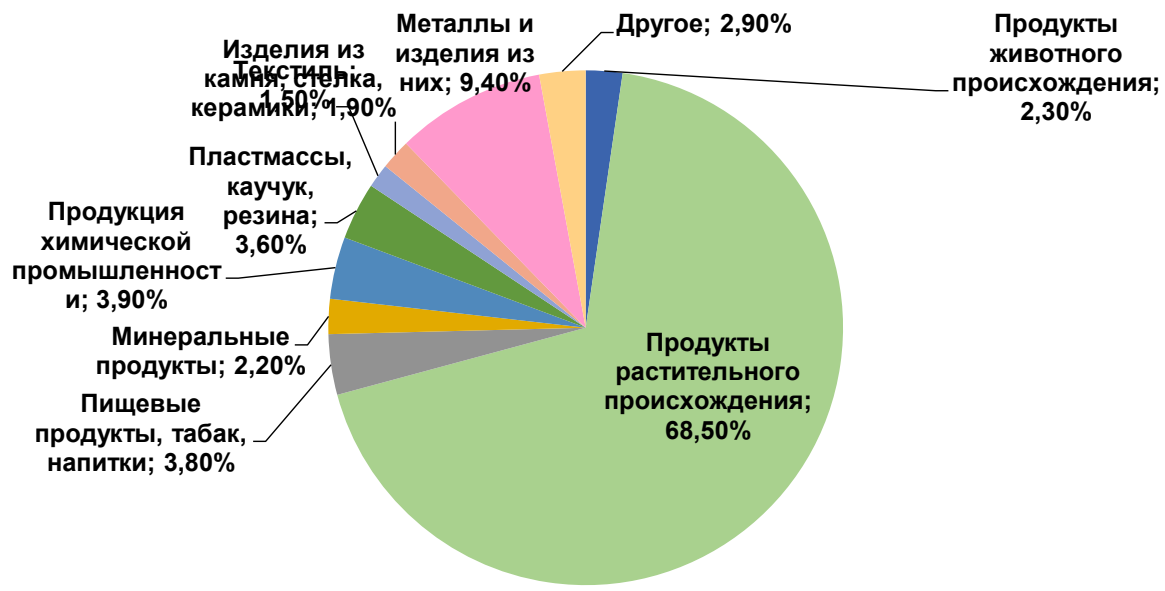

Рисунок 5. Товарная структура импорта из Ирана в Россию, \% Источник: составлено автором

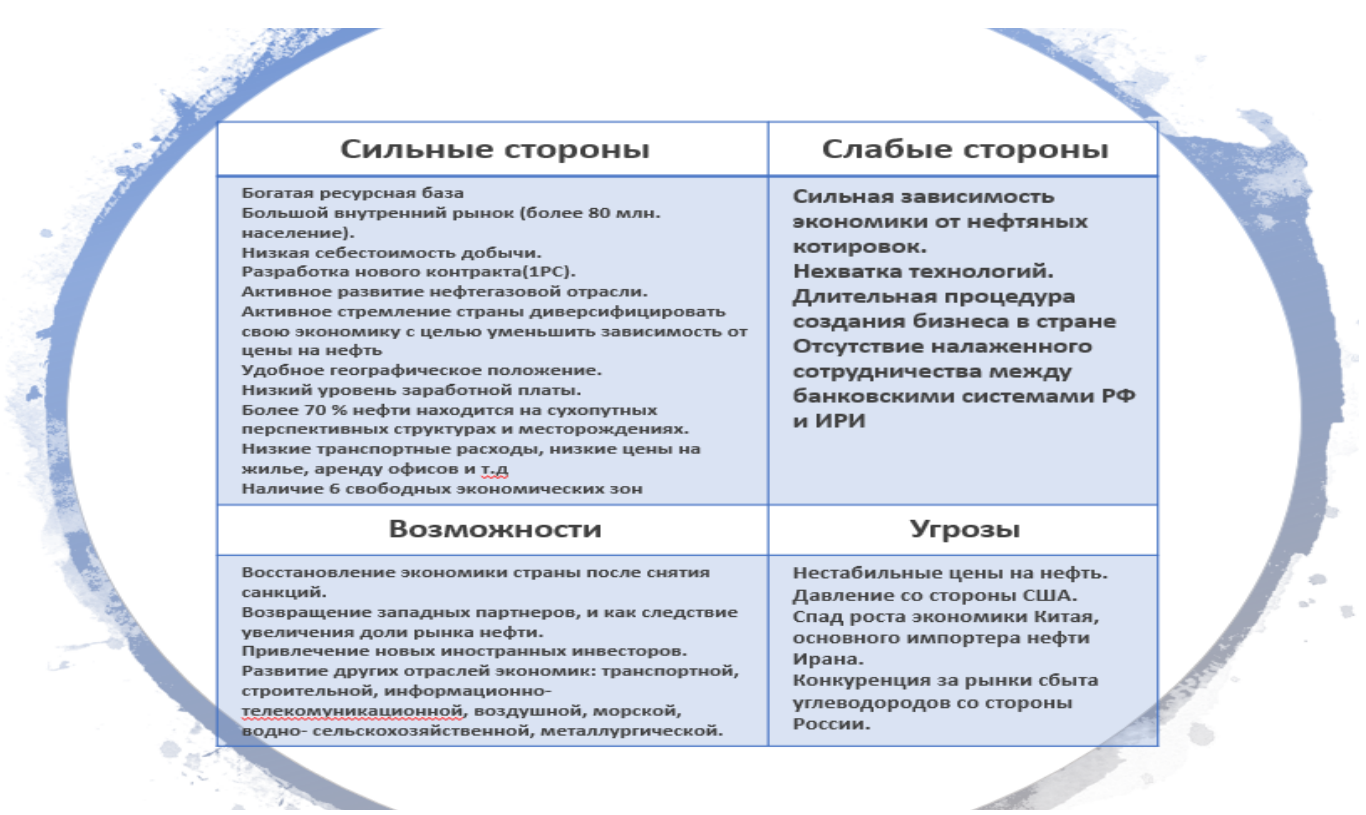

Рисунок 6. SWOT-анализ инвестиционной привлекательности Исламской республики Иран 
лей экономики. Такая ситуация очень благоприятна для российских компаний любого сектора экономики.

В связи с программой диверсификации экономики Иран заинтересован в привлечении инвестиции во всех отраслях: машиностроения, энергетики, транспорта, туристической инфраструктуры. В особенности, российским компаниям следует обратить внимание на область металлургии. В настоящее время иранское правительство начало реализацию программы модернизации и укрепления своей горнорудной и металлургической промышленности. В соответствии с данной программой к 2025 году мощности иранских металлургических предприятий по выплавке стали должны превысить 50 млн. тонн.

Учитывая значительный российский опыт в области черной металлургии, российские компании могли бы принять участие в строительстве предприятий горно-металлургического комплекса Ирана, в частности в строительстве заводов по обогащению железной руды и фабрик окомкования, предусмотренных планом освоения месторождений. В связи с намерениями правительства по увеличению добычи полезных ископаемых Иран нуждается в покупке специальной техники для извлечения и транспортировки руд, работы в шахтах.

Правительство Ирана также ведет закупку дорожно-строительной техники, экскаваторов, грейдеров и др. Вся необходимая Ирану подобная техника производится российскими машиностроительными промышленными группами.

Очень большой рынок Ирана в особенности интересен потребительским компаниям, ищущих новые рынки сбыта.

Компаниям нефтегазового сектора следует обратить внимание на замороженные перспективные проекты, связанные с месторождениями «Южный Парс» и «Дехлоран».

Для российских экспортеров устанавливаются преференциальные условия выхода на рынок Ирана.

Временное соглашение определяет следующие подходы в сфере развития торговли России и Ирана:

1. Противодействие дискриминации то- варов из России. В рамках соглашения Иран не должен дискриминировать товары из России и других стран ЕАЭС по сравнению с национальными товарами или импортными товарами из третьих государств. Кроме того, любые преференции, связанные с экспортом или импортом, предоставляемые со стороны Ирана третьей стране, будут безоговорочно предоставляться на аналогичные товары из России и других государств ЕАЭС.

2. Система бизнес-диалога. Создание специальных деловых площадок для взаимодействия представителей деловых сообщества Ирана и стран ЕАЭС, в частности России. Проведение выставок, семинаров, ярмарок, создающих основу для развития торговых отношений.

3. Сертификат происхождения. Для получения преференций экспортер должен предоставить в таможенный орган Сертификат о происхождении товара. В России данные сертификаты выдаются Торгово-промышленной палатой, а проверяются Минпромторгом России [2].

4. Упрощение таможенных процедур. Для повышения эффективности выпуска товаров стороны Временного соглашения обязались обеспечить выпуск товаров не более чем за 48 часов с момента регистрации таможенной декларации. Также по возможности вводится электронный таможенный документооборот.

Новое законодательство о привлечении иностранных инвестиций позволяет зарубежным компаниям создавать собственные предприятия в Иране со $100 \%$ участием в уставном капитале.

Препятствием на пути развития иранороссийских связей является отсутствие налаженного сотрудничества между банковскими системами двух стран, вследствие чего многие важные соглашения не действуют.

Еще один немаловажный фактор состоит в том, что «большинство политических, культурных, экономических и торговых институтов в Иране сталкиваются с проблемой дефицита специалистов, владеющих русским языком и хорошо знакомых с российскими реалиями. Это очень сильно скажется на доступности информации, которую российско-иранские партнеры будут получать друг о друге. 


\section{Библиографический список}

1. Временное соглашение о ЗСТ ЕАЭС - Иран: вызовы и перспективы [Электронный ресурс].- Режим доступа: http://eurasian-studies.org/archives/8772 (дата обращения: 23.04.2020).

2. Обзор ключевые положений Временного соглашения, ведущего к образованию зоны свободной торговли между ЕАЭС и Ираном [Электронный ресурс].- Режим доступа: http://www.eurasiancommission.org/ru/act/ trade/dotp/sogl_torg/Documents/Иран/Брошюра_Временное\%20соглашение\%20С\%20Ираном.pdf (дата обращения: 23.04.2020).

3. Руденко Д. Ю. Иерархическая структура глобальной цели социально-экономического развития региона [Электронный ресурс] / Д. Ю. Руденко // Современные проблемы науки и образования. 2013. № 5. Режим доступа: http://www.science-education.ru/111-10281/

4. Экспорт и импорт России по товарам и странам [Электронный ресурс].- Режим доступа: https://ru-stat. com/date-Y2017-2019/RU/import/IR (дата обращения: 23.04.2020).

5. Никифорова, Н.А. Стратегический анализ бизнес-процессов 3D. Данные, диагностика, действия: монография / Н.А.Никифорова, Т.Б.Иззука, С.Н. Миловидова; под ред. Н.А.Никифоровой.- Москва: РУСАЙНС, 2020.- 304 c. 